\title{
Alcohol consumption and prevalence of human papillomavirus (HPV) infection among US men in the HPV in Men (HIM) study
}

\author{
Matthew B Schabath, ${ }^{1,2}$ Zachary J Thompson, ${ }^{3}$ Kathleen M Egan, ${ }^{1}$ B Nelson Torres, ${ }^{1,2}$ \\ Anthony Nguyen, ${ }^{1}$ Mary R Papenfuss, ${ }^{1,2}$ Martha E Abrahamsen, 1,2 \\ Anna R Giuliano ${ }^{1,2}$
}

'Department of Cancer Epidemiology, H. Lee Moffitt Cancer Center and Research Institute, Tampa, Florida, USA ${ }^{2}$ Center for Infection Research in Cancer (CIRC), H. Lee Moffitt Cancer Center and Research Institute, Tampa, Florida, USA

${ }^{3}$ Department of Biostatistics and Bioinformatics, H. Lee Moffitt Cancer Center and Research Institute, Tampa, Florida, USA

\section{Correspondence to} Dr Matthew B Schabath, H. Lee Moffitt Cancer Center and Research Institute, 12902 Magnolia Drive MRCCANCONT, Tampa, FL 33612, USA; Matthew.Schabath@ Moffitt.org

Received 28 October 2013 Revised 30 June 2014 Accepted 27 July 2014 Published Online First 2 October 2014
CrossMark

\footnotetext{
To cite: Schabath $\mathrm{MB}$,

Thompson ZJ, Egan KM, et al. Sex Transm Infect
} 2015;91:61-67.

\begin{abstract}
Objectives Moderate alcohol consumption can impair host defence against viral infections. The objective of this cross-sectional analysis was to assess the association between alcohol intake and prevalent human papillomavirus (HPV) infection among US men enrolled in the HPV in Men (HIM) study using quantitative alcohol intake measured from a Food Frequency Questionnaire.
\end{abstract}

Methods The HIM study is a prospective, multinational study of the natural history of HPV infection. For this report, we restricted our analyses to men from the US cohort $(N=1313)$. Samples from the corona of glans penis, penile shaft and scrotum were combined for HPV DNA testing. Self-reported alcohol intake was quantified by grams of alcohol intake per day. Multivariable prevalence ratios (mPRs) were used to assess the association between alcohol intake and HPV infections. Results Prevalent infections were significantly higher among men in the highest quartile of alcohol intake and multivariable models revealed that the highest quartile of alcohol intake was associated with significantly increased risks for any (mPR=1.13; $95 \% \mathrm{Cl} 1.00$ to 1.27$) \mathrm{HPV}$ types and oncogenic (mPR=1.35; 95\% Cl 1.08 to 1.68 ) HPV types. The fourth quartile of alcohol intake was associated with elevated risks for prevalent HPV infection across all strata of number of sexual partners and among never-smokers and current smokers, but not among former smokers.

Conclusions These results demonstrate that high intake of alcohol is associated with an increased risk for prevalent HPV infections among men. The biological role that alcohol plays in genital HPV infection remains understudied and limited epidemiological data exist, especially among men.

\section{INTRODUCTION}

With more than six million new infections occurring annually in the USA, ${ }^{1}{ }^{2}$ human papillomavirus (HPV) is one of the most common sexually transmitted infections. There are more than 120 different HPV types, of which 40 or more types are transmitted through sexual contact. ${ }^{3}$ In addition to the clinical endpoints HPV causes in men, including genital warts and various cancers, HPV is readily transmitted from person to person and is strongly associated with cancer risk in women. ${ }^{4-6}$ Although the majority of HPV infections are transient and do not result in disease, the failure to develop an immune response to control an infection results in viral persistence and, in the case of the oncogenic HPV types, an increased risk of progression to cancer. ${ }^{7}$

Alcohol consumption is a potent modulator of immune function, which can lead to immune deficiency and increased susceptibility to various chronic and infectious diseases. ${ }^{8-11}$ Chronic alcohol abuse and acute and moderate alcohol consumption can adversely affect the immune system. $.^{9} 11-13$ Pathogen response is divided into two phases: the first phase is an inflammatory reaction, which provides protection against the immediate effects of the infection, and the second phase involves the development of immunity to the pathogen. Alcohol consumption can interfere with both phases of the immune response. ${ }^{9}$ The consequences of alcohol-induced immunodysfunction include increased susceptibility to numerous infectious endpoints, including bacterial pneumonia, septicaemia, tuberculosis and hepatitis. ${ }^{10} \quad 12 \quad 13$ Currently, there are few published data on the association between alcohol consumption and genital HPV infection among men. Revealing the association between a potential risk factor and prevalent HPV infections is an obligatory step prior to initiating longitudinal analyses of HPV infection endpoints. Thus, the objective of this analysis was to use alcohol consumption data from a Food Frequency Questionnaire (FFQ) to assess the association between alcohol intake and prevalent HPV infection among US men in the HPV in Men (HIM) study. To evaluate the potential effect modification, we also stratified the data by smoking status and lifetime number of sexual partners. Until now, this is one of the largest analyses exploring the association between alcohol intake and HPV infection.

\section{MATERIALS AND METHODS} \section{Study population and Risk Factor Questionnaire}

The human-subjects' committees from The University of South Florida (USF) approved all study procedures before study initiation (USF IRB\# 102660). The HIM study is a prospective, multinational study of the natural history of HPV infection in men; a full description of cohort procedures, HPV prevalence and factors associated with prevalent infections has been published. ${ }^{14} 15$ For this report, we restricted our analysis to men 
from the US cohort because of potential regional and cultural differences in alcohol consumption (ie, types of alcohol, frequency of use and age of initiation) and behaviour. Men who provided informed consent had a clinical examination 2 weeks prior to the enrolment visit $(\mathrm{N}=1427)$ and every 6 months thereafter. Only men who returned for the enrolment visit $(\mathrm{N}=1313)$ from 2005 through 2006 were included in this report.

An extensive Sexual History and Health Questionnaire, which required approximately $15 \mathrm{~min}$ to complete, was administered at the enrolment visit to assess sociodemographic information and risk factors. Using the US Centers for Disease Control definition, ${ }^{16}$ never-smokers were defined as men who had smoked $<100$ cigarettes in their lifetime. Likewise, ${ }^{17}$ former smokers were defined as men who had smoked at least 100 cigarettes in their lifetime but quit smoking at least 1 year before the enrolment interview. Current smokers were defined as men who smoked at least 100 cigarettes in their lifetime and were currently smoking (or quit within the previous 12 months) at the time of the enrolment visit.

\section{Arizona Food Frequency Questionnaire (AFFQ)}

The Arizona Food Frequency Questionnaire (AFFQ) is a modification of the National Cancer Institute's Health Habits and History $\mathrm{FFQ}^{18}$ that consists of a semiquantitative 159 -item questionnaire which asks respondents to report how often they usually consumed each particular item over the prior 12-month period. The AFFQ was completed by the men at the enrolment visit and required about $30 \mathrm{~min}$ to complete. The AFFQ contained questions on alcohol consumption including serving size and frequency of light beer, beer, wine and liquor. Serving size was subjectively defined as the average serving size compared with other men of the same age and classified as small, medium or large. Frequency of consumption was collected as 6+ times per day, 3-5 times per day, twice a day, once a day, 5-6 times a week, 2-4 times a week, once a week, 1-3 times a month and rarely/never. The FFQ analysis programme quantified alcohol intake by grams of alcohol intake per day and per cent calories from alcohol per day. All findings were consistent when alcohol intake was evaluated according to per cent calories from alcohol per day. In this report, we present results for grams of alcohol intake per day.

\section{Sample collection, DNA extraction and HPV genotyping}

Details of sample collection, DNA extraction and HPV genotyping have been published elsewhere. ${ }^{14}{ }^{15}$ Briefly, three separate specimens were obtained from the corona of glans penis, penile shaft and scrotum, placed into $450 \mu \mathrm{L}$ of Specimen Transport Medium and then combined into one sample before DNA extraction. The extracted DNA samples were tested for the presence of HPV types by amplification with the PGMY09/11 L1 consensus primer system ${ }^{19} 20$ and HPV genotyping was performed with the Linear Array method on all samples irrespective of the HPV PCR result (Roche Molecular Diagnostics, Alameda, California, USA). Only samples that tested positive for $\beta$-globin (99\% at enrolment) were judged to be adequate and included in the analysis.

\section{Statistical analysis}

Four HPV categories were assessed in this analysis (ie, 'any HPV', 'oncogenic HPV', 'non-oncogenic HPV' and 'quadrivalent vaccine types'). A participant was considered positive for 'any HPV' if he tested HPV positive by PCR or tested positive for at least one genotype. The 'oncogenic HPV' category included men who were positive for at least one of the 13 oncogenic types tested (HPV types 16, 18, 31, 33, 35, 39, 45, $51,52,56,58,59$ and 66) and included men infected with both oncogenic and non-oncogenic types. 'Non-oncogenic HPV' infections included single or multiple infections with only non-oncogenic HPV types (6, 11, 26, 40, 42, 53, 54, 55, 61, $62,64,67,68-73,81-84$, IS39 and CP6108). The 'quadrivalent vaccine types' included men with one or more prevalent infections of HPV 6, 11, 16 or 18.

All statistical analyses were performed using R V.2.14 (R Project for Statistical Computing, http://www.r-project.org) and SAS V.9.3 (Cary, North Carolina, USA). Alcohol intake was categorised by the quartile intake values among HPV-negative men. Sociodemographic and sexual behavioural cohort characteristics across quartiles of alcohol intake were compared by using Fisher's exact test. The Wilcoxon rank-sum test was used to test for differences in the median alcohol intake and the Pearson's $\chi^{2}$ test was used to test for differences in the distribution of HPV positivity across quartiles of alcohol intake. Multivariable Poisson regression (PROC GENMOD) was used to generate prevalence ratios (PRs) and 95\% CIs.

\section{RESULTS}

Alcohol consumption was categorised according to quartiles of grams (g) of alcohol intake per day among HPV-negative men: $\mathrm{Q} 1<0.10 \mathrm{~g} /$ day; $\mathrm{Q} 2 \geq 0.10$ to $<3.13 \mathrm{~g} /$ day; $\mathrm{Q} 3 \geq 3.13$ to $<9.91 \mathrm{~g} /$ day and Q4 $\geq 9.91 \mathrm{~g} /$ day (table 1 ). The mean (SD) of grams of alcohol intake per day was $0.02 \mathrm{~g} /$ day $(0.02), 1.69 \mathrm{~g} /$ day (0.84), $5.88 \mathrm{~g} /$ day (2.02) and $35.9 \mathrm{~g} /$ day (39.8) in quartiles $1-4$, respectively. Statistically significant differences were observed for the distribution of study population characteristics by quartiles of alcohol intake. Men who consumed higher levels of alcohol (quartiles 3 and 4) were younger, current smokers, White, reported more female sexual partners and were more likely to be circumcised (table 1).

Compared with HPV-negative men, the median intake of alcohol was significantly higher among HPV-positive men (table 2). The median alcohol intake per day among HPV-negative men was $3.13 \mathrm{~g}$ (IQR 0.1-9.9) compared with men who were positive for any HPV types (median=4.52 g; IQR $0.6-15.5 ; \mathrm{p}<0.001$ ), the oncogenic HPV types (median=5.23 g; IQR 1.1-18.3; p<0.001), the non-oncogenic HPV types (median=5.29 g; IQR 0.6-17.5; $\mathrm{p}=0.006$ ) and the quadrivalent vaccine HPV types (median $6.31 \mathrm{~g}$; IQR 1.2-19.4; $\mathrm{p}<0.001$ ). When HPV prevalence was analysed by quartiles of alcohol intake (table 2), we noted a significantly higher prevalence of HPV among men in the highest quartile of alcohol consumption. Across the four quartiles of alcohol intake, the prevalence was $56.7 \%, 56.2 \%, 57.9 \%$ and $68.9 \%$ for any HPV types $(\mathrm{p}<0.001) ; 22.8 \%, 24.7 \%, 27.0 \%$ and $35.2 \%$ for oncogenic HPV types $(\mathrm{p}<0.001) ; 16.1 \%, 12.0 \%, 15.5 \%$ and $19.5 \%$ for non-oncogenic HPV types $(\mathrm{p}=0.002)$ and $11.7 \%, 12.0 \%$, $15.1 \%$ and $19.5 \%$ for the quadrivalent vaccine HPV types $(\mathrm{p}<0.001)$.

In table 3, we present the multivariable prevalence ratios (mPRs) for the association between alcohol intake and HPV infection, adjusting for potential confounders including age, race, smoking status, ethnicity, circumcision, total number of female partners in the last 3 months and total number of female sexual partners. Overall, the highest quartile (Q4) of alcohol intake compared with the lowest quartile (Q1) was significantly associated with an increased risk for any HPV types $(\mathrm{mPR}=1.12 ; 95 \% \mathrm{CI} 1.03$ to 1.27$)$ and oncogenic HPV types $(\mathrm{mPR}=1.35 ; 95 \% \mathrm{CI} 1.08$ to 1.68$)$, and a borderline significant increased risk for the quadrivalent vaccine HPV types 
Table 1 HIM study demographics among US men overall and by quartiles of alcohol intake

\begin{tabular}{|c|c|c|c|c|c|c|}
\hline \multirow[b]{2}{*}{ Characteristic* } & \multirow[b]{2}{*}{$\begin{array}{l}\text { Overall } \\
(\mathrm{N}=1309)\end{array}$} & \multicolumn{5}{|c|}{ By grams of alcohol intake per dayt } \\
\hline & & $\begin{array}{l}\text { Q1 } \\
(\mathrm{N}=298)\end{array}$ & $\begin{array}{l}\text { Q2 } \\
(\mathrm{N}=292)\end{array}$ & & $\begin{array}{l}\text { Q3 } \\
(\mathrm{N}=304)\end{array}$ & $\begin{array}{l}\mathrm{Q4} \\
(\mathrm{N}=415)\end{array}$ \\
\hline \multicolumn{7}{|l|}{ Alcohol intake per day, grams } \\
\hline IQR & 0.56 to 13.4 & $<0.10$ & $\geq 0.10$ to $<3.13$ & & $\geq 3.13$ to $<9.91$ & $\geq 9.91$ \\
\hline Mean (SD) within each quartile & $12.8(27.1)$ & $0.02(0.02)$ & $1.69(0.84)$ & & $5.88(2.02)$ & $35.9(39.8)$ \\
\hline \multicolumn{7}{|l|}{ Age } \\
\hline Mean (SD) & $29.2(12.6)$ & $31.3(13.7)$ & $29.8(12.6)$ & & $27.2(10.9)$ & $28.6(12.6)$ \\
\hline$p$ Value & & & & $<0.001$ & & \\
\hline \multicolumn{7}{|l|}{ Categorical, N (\%) } \\
\hline $18-24$ & $720(55.0)$ & $141(47.3)$ & $151(51.7)$ & & $184(60.5)$ & $244(58.8)$ \\
\hline $25-29$ & $123(9.4)$ & $24(8.1)$ & $23(7.9)$ & & $35(11.5)$ & $41(9.9)$ \\
\hline $30-44$ & $292(22.3)$ & $74(24.8)$ & $85(29.1)$ & & $56(18.4)$ & 77 (18.6) \\
\hline$\geq 45$ & $174(13.3)$ & $59(19.8)$ & $33(11.3)$ & & $29(9.5)$ & $53(12.8)$ \\
\hline $\mathrm{p}$ Value & & & & $<0.001$ & & \\
\hline \multicolumn{7}{|l|}{ Smoking status, N (\%) } \\
\hline Never & $836(63.7)$ & $194(65.1)$ & $211(72.3)$ & & $206(67.8)$ & $225(54.2)$ \\
\hline Former & $206(15.7)$ & $51(17.1)$ & $29(9.9)$ & & $44(14.5)$ & $82(19.8)$ \\
\hline Current & $267(20.3)$ & $53(17.8)$ & $52(17.8)$ & & $54(17.8)$ & $108(26.0)$ \\
\hline $\mathrm{p}$ Value & & & & $<0.001$ & & \\
\hline \multicolumn{7}{|l|}{ Race, N (\%) } \\
\hline White & $873(66.7)$ & $182(61.1)$ & $174(59.6)$ & & $208(68.4)$ & $309(74.5)$ \\
\hline Black & $230(17.6)$ & $67(22.5)$ & $59(20.2)$ & & $42(13.8)$ & $62(14.9)$ \\
\hline Asian/Pacific Islander & $85(6.5)$ & $21(7.0)$ & $30(10.3)$ & & $21(6.9)$ & $13(3.1)$ \\
\hline American Indian & $2(0.2)$ & $1(0.3)$ & $0(0.0)$ & & $0(0.0)$ & $1(0.2)$ \\
\hline Mixed/unknown/refused & $119(9.1)$ & $27(9.1)$ & $29(9.9)$ & & $33(10.9)$ & $30(7.2)$ \\
\hline $\mathrm{p}$ Value & & & & $<0.001$ & & \\
\hline \multicolumn{7}{|l|}{ Ethnicity, N (\%) } \\
\hline Hispanic & $199(15.2)$ & 37 (12.4) & $55(18.8)$ & & $46(15.1)$ & $61(14.7)$ \\
\hline Non-Hispanic & $1100(83.8)$ & $257(86.2)$ & $236(80.8)$ & & $255(83.9)$ & $352(84.8)$ \\
\hline Refused & $10(0.8)$ & $4(1.3)$ & $1(0.3)$ & & $3(1.0)$ & $2(0.5)$ \\
\hline $\mathrm{p}$ Value & & & & 0.294 & & \\
\hline \multicolumn{7}{|c|}{ Lifetime number of female sexual partners, $\mathrm{N}(\%)$} \\
\hline 0 & $141(10.8)$ & $44(14.8)$ & $38(13.0)$ & & $32(10.5)$ & $27(6.5)$ \\
\hline 1 & $130(9.9)$ & $38(12.8)$ & $41(14.0)$ & & $32(10.5)$ & $19(4.6)$ \\
\hline $2-9$ & $502(38.3)$ & $92(30.9)$ & $117(40.1)$ & & $119(39.1)$ & $174(41.9)$ \\
\hline $10-19$ & $204(15.6)$ & $43(14.4)$ & $44(15.1)$ & & $45(14.8)$ & $72(17.3)$ \\
\hline $20-49$ & $199(15.2)$ & $43(14.4)$ & $26(8.9)$ & & $51(16.8)$ & $79(19.0)$ \\
\hline$\geq 50$ & $92(7.0)$ & $25(8.4)$ & $21(7.2)$ & & $16(5.3)$ & $30(7.2)$ \\
\hline Refused & $41(3.1)$ & $13(4.4)$ & $5(1.7)$ & & $9(3.0)$ & $14(3.4)$ \\
\hline $\mathrm{p}$ Value & & & & $<0.001$ & & \\
\hline \multicolumn{7}{|c|}{ Total number of female partners in the last 3-6 months, $\mathrm{N}(\%)$} \\
\hline 0 & $141(10.8)$ & $44(14.8)$ & $38(13.0)$ & & $32(10.5)$ & $27(6.5)$ \\
\hline 1 & $856(65.4)$ & $212(71.1)$ & $209(71.6)$ & & $194(63.8)$ & $241(58.1)$ \\
\hline 2 & $128(9.8)$ & $17(5.7)$ & $24(8.2)$ & & $37(12.2)$ & $50(12.0)$ \\
\hline 3 & $171(13.1)$ & $22(7.4)$ & $21(7.2)$ & & $39(12.8)$ & 89 (21.4) \\
\hline Refused & $13(1.0)$ & $3(1.0)$ & $0(0.0)$ & & $2(0.7)$ & $8(1.9)$ \\
\hline $\mathrm{p}$ Value & & & & $<0.001$ & & \\
\hline \multicolumn{7}{|l|}{ Circumcision, N (\%) } \\
\hline Yes & 1029 (78.4) & $224(75.2)$ & $224(75.2)$ & & 212 (72.6) & $240(78.9)$ \\
\hline No & 247 18.8) & $67(22.5)$ & $67(22.5)$ & & $67(22.9)$ & $57(18.8)$ \\
\hline Partial & $33(2.5)$ & $7(2.3)$ & $7(2.3)$ & & $13(4.5)$ & $7(2.3)$ \\
\hline $\mathrm{p}$ Value & & & & 0.002 & & \\
\hline \multicolumn{7}{|c|}{ Total number of male partners in the last 3-6 months, $\mathrm{N}(\%)$} \\
\hline 0 & $1269(96.9)$ & $295(99.0)$ & $281(96.2)$ & & $293(96.4)$ & $400(96.4)$ \\
\hline$\geq 1$ & $40(3.1)$ & $3(1.0)$ & $11(3.8)$ & & $11(3.6)$ & $15(3.6)$ \\
\hline $\mathrm{p}$ Value & & & & 0.140 & & \\
\hline \multicolumn{7}{|c|}{ Lifetime number of male sexual partners, $\mathrm{N}(\%)$} \\
\hline 0 & $1233(94.2)$ & $284(95.3)$ & $272(93.2)$ & & $286(94.1)$ & 391 (94.2) \\
\hline
\end{tabular}


Table 1 Continued

\begin{tabular}{|c|c|c|c|c|c|}
\hline \multirow[b]{2}{*}{ Characteristic* } & \multirow[b]{2}{*}{$\begin{array}{l}\text { Overall } \\
(\mathrm{N}=1309)\end{array}$} & \multicolumn{4}{|c|}{ By grams of alcohol intake per dayt } \\
\hline & & $\begin{array}{l}\text { Q1 } \\
(\mathrm{N}=298)\end{array}$ & $\begin{array}{l}\text { Q2 } \\
(N=292)\end{array}$ & $\begin{array}{l}\text { Q3 } \\
(\mathrm{N}=304)\end{array}$ & $\begin{array}{l}\text { Q4 } \\
(\mathrm{N}=415)\end{array}$ \\
\hline 1 & $23(1.8)$ & $6(2.0)$ & $5(1.7)$ & $9(3.0)$ & $3(0.7)$ \\
\hline $2+$ & $53(4.1)$ & $8(2.7)$ & $15(5.2)$ & $9(3.0)$ & $21(5.1)$ \\
\hline p Value & & & & & \\
\hline \multicolumn{6}{|c|}{$\begin{array}{l}\text { Bold font indicates a statistically significant } p \text { value. } \\
{ }^{*} p \text { Values were calculated from the Fisher's exact test for the categorical variables by quartiles of alcohol intake and analysis of variance for the continuous variable (ie, age) by } \\
\text { quartiles of alcohol intake. All } p \text { values are two sided. } \\
\text { †Alcohol intake was categorised by the quartile intake values among human papillomavirus (HPV)-negative men. } \\
\text { HIM, HPV in Men; Qn., quartile. }\end{array}$} \\
\hline
\end{tabular}

$(\mathrm{mPR}=1.47 ; 95 \%$ CI 0.98 to 2.23$)$. To increase statistical power, we also assessed alcohol intake by combining the first three quartiles of intake into a new referent group. As evident in table 2, HPV prevalence was similar for the first three quartiles (table 2) and the overall point estimates (table 3 ) for the first three quartiles clustered around 1.00. Generally, the point estimates for Q4 were similar, but the CIs were narrower. We did not adjust for sex with male partners since over $94 \%$ of the men in this analysis reported having zero male partners and there was no difference $(p=0.739)$ across quartiles of alcohol intake as noted in table 1 . We performed an exploratory analysis that included number of male sexual partners in the model and also restricted to men who reported zero male sexual partners; however, there was no appreciable difference in the point estimates (data not shown).

We also stratified the analyses by smoking status. Significant associations were observed for high intake (Q4) and HPV prevalence among never-smokers for any HPV types $(\mathrm{PR}=1.22 ; 95 \%$ CI 1.03 to 1.44$)$ and oncogenic HPV types ( $P R=1.48 ; 95 \%$ CI 1.09 to 2.02), and borderline significant associations for the non-oncogenic HPV types and quadrivalent vaccine HPV types. There were no statistically significant associations among former smokers. We noted borderline significant associations among current smokers for high alcohol intake (Q4) compared with the grouped referent (Q1-Q3) for any HPV infections $(\mathrm{mPR}=1.14 ; 95 \%$ CI 0.95 to 1.37$)$ and oncogenic HPV infections $(\mathrm{HR}=1.26 ; 95 \% \mathrm{CI} 0.98$ to 1.70$)$.

We also stratified the association between alcohol intake and HPV infection by lifetime number of sexual partners $(0-1,2-9$ and $\geq 10)$. For these analyses, we used the grouped referent (Q1-Q3) and found that high alcohol intake (Q4) was associated with relatively modest elevated point estimates across all strata of number of sexual partners (table 4 ).

\section{DISCUSSION}

Assessing the impact of a potential risk factor and prevalent HPV infections is an important step prior to initiating longitudinal analyses. Thus, this study sought to assess the association between self-reported alcohol intake and prevalent HPV infections among US men. Our analyses revealed that prevalent infections were significantly higher among men in the highest quartile of alcohol intake and multivariable analyses, adjusting for potential confounders, including sexual behaviour and smoking, revealed that the highest quartile of alcohol intake was associated with an increased risk of prevalent genital HPV infection. Furthermore, we found no evidence of confounding by sexual behaviour and smoking following stratification by these risk factors.

The association between alcohol consumption and HPV-related endpoints has been reported in other study populations. A cross-sectional study of men in the Danish Army reported that alcohol intake was associated with having multiple HPV types. ${ }^{21}$ A prospective study of the natural history of cervicovaginal papillomavirus infection in women ${ }^{22}$ found an elevated risk (relative risk $=2.0 ; 95 \%$ CI 1.2 to 3.1 ) of incident HPV infection associated with high alcohol consumption. A cross-sectional study that assessed sexual practices and cervical HPV infection among college women ${ }^{23}$ reported alcohol use was significantly

Table 2 Alcohol intake by human papillomavirus (HPV) infection status and HPV prevalence by quartiles of alcohol intake

\begin{tabular}{|c|c|c|c|c|c|c|c|c|c|}
\hline & \multirow[b]{2}{*}{ No. } & \multicolumn{3}{|c|}{$\begin{array}{l}\text { Median grams of alcohol intake per } \\
\text { day by HPV infection status }\end{array}$} & \multicolumn{5}{|c|}{ HPV prevalence by quartiles* of grams of alcohol intake per day } \\
\hline & & Median & (IQR) & p Valuet & $\begin{array}{l}\text { Q1 } \\
N(\%)\end{array}$ & $\begin{array}{l}\text { Q2 } \\
\mathrm{N}(\%)\end{array}$ & $\begin{array}{l}\text { Q3 } \\
N(\%)\end{array}$ & $\begin{array}{l}\text { Q4 } \\
\mathrm{N}(\%)\end{array}$ & $p$ Value $\ddagger$ \\
\hline HPV negative & 514 & 3.13 & $(0.1-9.9)$ & & $129(43.3)$ & $128(43.8)$ & $128(42.1)$ & $129(31.1)$ & \\
\hline \multicolumn{10}{|l|}{ Positive for: } \\
\hline Any HPV & 795 & 4.52 & $(0.6-15.5)$ & $<0.001$ & $169(56.7)$ & $164(56.2)$ & $176(57.9)$ & $286(68.9)$ & $<0.001$ \\
\hline Oncogenic HPV & 368 & 5.23 & $(1.1-18.3)$ & $<0.001$ & $68(22.8)$ & $72(24.7)$ & $82(27.0)$ & $146(35.2)$ & $<0.001$ \\
\hline Non-oncogenic HPV & 211 & 5.29 & $(0.6-17.5)$ & 0.006 & $48(16.1)$ & $35(12.0)$ & $47(15.5)$ & $81(19.5)$ & 0.002 \\
\hline HPV $6,11,16$ or $18 \S$ & 197 & 6.31 & $(1.2-19.4)$ & $<0.001$ & 35 (11.7) & $35(12.0)$ & $46(15.1)$ & 81 (19.5) & $<0.001$ \\
\hline \multicolumn{10}{|c|}{$\begin{array}{l}\text { Bold font indicates a statistically significant } p \text { value. } \\
\text { *Alcohol intake was categorised by the quartile intake values among HPV-negative men. } \\
\text { tp Values were calculated using the Wilcoxon rank-sum test comparing the median value of alcohol consumption by HPV negativity versus HPV positivity. } \\
\text { fp Values were calculated by the } \chi^{2} \text { test for the distribution of HPV positivity compared with HPV negativity by quartiles of alcohol intake. The percentages presented are prevalence } \\
\text { using the total number of subjects within each quartile of intake as the denominator. } \\
\text { \$HPV 6, } 11,16 \text { or } 18 \text { are the quadrivalent vaccine HPV types. } \\
\text { Qn, quartile. }\end{array}$} \\
\hline
\end{tabular}


Table 3 Risk of prevalent human papillomavirus (HPV) infection by quartiles of alcohol intake stratified by smoking status*

\begin{tabular}{|c|c|c|c|c|}
\hline \multirow[b]{2}{*}{ HPV status } & \multirow[b]{2}{*}{$\begin{array}{l}\text { Overall ( } N=1309 \text { ) } \\
\text { mPRt‡ }\end{array}$} & \multicolumn{3}{|l|}{ By smoking status } \\
\hline & & $\begin{array}{l}\text { Never-smokers }(\mathrm{N}=836) \\
\mathrm{mPR} \ddagger \S\end{array}$ & $\begin{array}{l}\text { Former smokers }(\mathrm{N}=206) \\
\mathrm{mPR} \neq \S\end{array}$ & $\begin{array}{l}\text { Current smokers }(\mathrm{N}=267) \\
\mathrm{mPR} \neq \S\end{array}$ \\
\hline \multicolumn{5}{|l|}{ Any HPV } \\
\hline Q1 & 1.00 (referent) & 1.00 (referent) & 1.00 (referent) & 1.00 (referent) \\
\hline Q2 & $1.01(0.88-1.16)$ & $1.16(0.97-1.39)$ & $0.72(0.39-1.34)$ & $0.81(0.62-1.06)$ \\
\hline Q3 & $1.00(0.88-1.15)$ & $1.11(0.92-1.33)$ & $0.83(0.48-1.43)$ & $0.80(0.61-1.06)$ \\
\hline Q4 & $1.13(1.00-1.27)$ & $1.22(1.03-1.44)$ & $0.90(0.57-1.42)$ & $0.99(0.79-1.23)$ \\
\hline Q1-Q3 & 1.00 (referent) & 1.00 (referent) & 1.00 (referent) & 1.00 (referent) \\
\hline Q4 & $1.12(1.03-1.23)$ & $1.12(0.99-1.26)$ & $1.03(0.72-1.48)$ & $1.14(0.95-1.37)$ \\
\hline \multicolumn{5}{|l|}{ Oncogenic } \\
\hline Q1 & 1.00 (referent) & 1.00 (referent) & 1.00 (referent) & 1.00 (referent) \\
\hline Q2 & $1.09(0.85-1.42)$ & $1.38(0.99-1.90)$ & $0.54(0.17-1.68)$ & $0.77(0.48-1.24)$ \\
\hline Q3 & $1.11(0.87-1.43)$ & $1.25(0.90-1.75)$ & $1.01(0.46-2.25)$ & $0.75(0.46-1.23)$ \\
\hline Q4 & $1.35(1.08-1.68)$ & $1.48(1.09-2.02)$ & $1.10(0.54-2.23)$ & $1.04(0.71-1.53)$ \\
\hline Q1-Q3 & 1.00 (referent) & 1.00 (referent) & 1.00 (referent) & 1.00 (referent) \\
\hline Q4 & $1.26(1.07-1.47)$ & $1.23(0.99-1.52)$ & $1.20(0.70-2.04)$ & $1.26(0.94-1.70)$ \\
\hline \multicolumn{5}{|c|}{ Non-oncogenic } \\
\hline Q1 & 1.00 (referent) & 1.00 (referent) & 1.00 (referent) & 1.00 (referent) \\
\hline Q2 & $0.78(0.50-1.22)$ & $1.01(0.55-1.85)$ & $0.69(0.25-1.89)$ & $0.58(0.24-1.43)$ \\
\hline Q3 & $0.98(0.65-1.48)$ & $1.31(0.75-2.28)$ & $0.66(0.23-1.85)$ & $0.73(0.31-1.69)$ \\
\hline Q4 & $1.20(0.83-1.74)$ & $1.56(0.91-2.67)$ & $0.89(0.38-2.06)$ & $0.90(0.44-1.84)$ \\
\hline Q1-Q3 & 1.00 (referent) & 1.00 (referent) & 1.00 (referent) & 1.00 (referent) \\
\hline Q4 & $1.30(0.97-1.73)$ & $1.39(0.93-2.08)$ & $1.15(0.60-2.20)$ & $1.18(0.67-2.07)$ \\
\hline \multicolumn{5}{|c|}{ HPV $6,11,16$ or 189} \\
\hline Q1 & 1.00 (referent) & 1.00 (referent) & 1.00 (referent) & 1.00 (referent) \\
\hline Q2 & $1.01(0.63-1.61)$ & $1.41(0.77-2.55)$ & $0.26(0.03-2.17)$ & $0.69(0.26-1.80)$ \\
\hline Q3 & $1.15(0.73-1.79)$ & $1.33(0.73-2.41)$ & $0.96(0.31-2.92)$ & $0.65(0.25-1.74)$ \\
\hline Q4 & $1.47(0.98-2.23)$ & $1.73(0.99-3.03)$ & $0.75(0.25-2.25)$ & $1.14(0.52-2.50)$ \\
\hline Q1-Q3 & 1.00 (referent) & 1.00 (referent) & 1.00 (referent) & 1.00 (referent) \\
\hline Q4 & $1.39(1.04-1.88)$ & $1.40(0.93-2.09)$ & $0.86(0.38-1.92)$ & $1.50(0.84-2.67)$ \\
\hline
\end{tabular}

Bold font indicates a statistically significant $\mathrm{HR}$.

${ }^{*}$ Alcohol intake was categorised by the quartile intake values among HPV-negative men.

†Adjusted for age, race, smoking status, ethnicity, circumcision and total number of female partners in the last 3 months.

$\neq$ We did not adjust for sex with male partners since over $94 \%$ of the men in this analysis reported having zero male partners and there was no difference ( $p=0.739$ ) across quartiles of alcohol intake as noted in Table 1.

§Adjusted for age, race, ethnicity, circumcision and total number of female partners in the last 3 months.

१HPV $6,11,16$ or 18 are the quadrivalent vaccine HPV types.

$\mathrm{mPR}$, multivariable prevalence ratio; $\mathrm{Q} n$, quartile.

more frequent among women who were HPV DNA positive. A case-control study of both sexes from four clinics in Washington state $^{24}$ reported that four alcoholic drinks/week was associated with nearly a twofold increased risk of genital warts $(95 \%$ CI 1.0 to 3.6) and five or more alcoholic drinks/week revealed a 2.4-fold increased risk (95\% CI 1.2 to 5.1). Conversely, two studies found no relationship between alcohol intake and HPV endpoints. A cross-sectional analysis of women seeking contraceptive advice in three Swedish clinics reported that recent use of alcohol was not associated with cervical HPV infection after adjustment for sexual/behavioural factors. ${ }^{25}$ In a separate study among high-risk HPV-positive women, alcohol intake was not associated with risk of high-grade squamous intraepithelial lesions. $^{26}$ In spite of some inconsistencies in the literature, evidence suggests a modest association between alcohol consumption and prevalent HPV infection.

Previous studies in both men and women have shown that cigarette smoking is associated with HPV prevalence, ${ }^{27} 28$ incidence $^{29}$ and persistence. ${ }^{30}$ We found significant point estimates for the association between alcohol consumption and HPV infection among never-smokers and borderline significant associations among current smokers. The observed effects among never-smokers are novel and of potential public health importance as there are few risk factors for HPV infection among never-smokers.

It is plausible that the association between higher alcohol intake and HPV infection could be due to increased sexual disinhibition and promiscuous sexual behaviour. To account for potential confounding, we adjusted for sexual activity in the multivariable models and we stratified by lifetime number of sexual partners to reveal potential effect modification by sexual activity. Interestingly, the stratified analyses demonstrated that high alcohol intake was generally associated with a modest increased risk of HPV risk infection regardless of the number of sexual partners. If increased sexual behaviour is solely responsible for our findings, we would have expected to see no association between high alcohol intake and HPV after adjustment and elevated effects only in the highest sexual activity strata. Because differences in sexual behaviour by alcohol intake do not appear to explain our findings, the observed associations could be due to other factors such as the systemic effects of alcohol on immune function. The immune system serves as a defence against infections, and alcohol consumption is a potent modulator of immune function. ${ }^{8-11}$ Studies in laboratory 
Table 4 Risk of prevalent human papillomavirus (HPV) infection by quartiles of alcohol intake stratified by lifetime number of sexual partners*

\begin{tabular}{|c|c|c|c|}
\hline \multirow[b]{2}{*}{ HPV status } & \multicolumn{3}{|c|}{ By lifetime number of sexual partners } \\
\hline & $\begin{array}{l}0-1 \\
(\mathrm{~N}=719) \\
\mathrm{mPR}+\end{array}$ & $\begin{array}{l}2-9 \\
(\mathrm{~N}=302) \\
\mathrm{mPR} \dagger\end{array}$ & $\begin{array}{l}\geq 10 \\
(\mathrm{~N}=288) \\
\mathrm{mPR} \dagger\end{array}$ \\
\hline \multicolumn{4}{|l|}{ Any HPV } \\
\hline Q1-Q3 & 1.00 (referent) & 1.00 (referent) & 1.00 (referent) \\
\hline Q4 & $1.14(1.00-1.29)$ & $1.17(0.96-1.44)$ & $1.16(1.01-1.33)$ \\
\hline \multicolumn{4}{|l|}{ Oncogenic } \\
\hline Q1-Q3 & 1.00 (referent) & 1.00 (referent) & 1.00 (referent) \\
\hline Q4 & $1.36(1.09-1.70)$ & $1.41(0.93-2.12)$ & $1.32(0.90-1.96)$ \\
\hline \multicolumn{4}{|c|}{ Non-oncogenic } \\
\hline Q1-Q3 & 1.00 (referent) & 1.00 (referent) & 1.00 (referent) \\
\hline Q4 & $1.21(0.87-1.69)$ & $1.96(1.09-3.51)$ & $1.32(0.79-2.20)$ \\
\hline \multicolumn{4}{|c|}{ HPV $6,11,16$ or $18 \ddagger$} \\
\hline Q1-Q3 & 1.00 (referent) & 1.00 (referent) & 1.00 (referent) \\
\hline Q4 & $1.58(1.11-2.25)$ & $1.58(0.93-2.67)$ & $1.30(0.76-2.26) \S$ \\
\hline \multicolumn{4}{|c|}{$\begin{array}{l}\text { Bold font indicates a statistically significant HR. } \\
\text { *Alcohol intake was categorised by the quartile intake values among HPV-negative } \\
\text { men and the first three quartiles were combined for the referent category. Lifetime } \\
\text { number of sexual partners was defined as men who have sex with women and/or } \\
\text { men. } \\
\text { tAdjusted for age, race, smoking status, ethnicity and circumcision unless otherwise } \\
\text { noted. } \\
\text { fHPV } 6,11,16 \text { or } 18 \text { are the quadrivalent vaccine HPV types. } \\
\text { §Because of small sample size, we could not adjust for race. Adjusted for age, } \\
\text { smoking status, ethnicity and circumcision. } \\
\text { mPR, multivariable prevalence ratio; Qn, quartile. }\end{array}$} \\
\hline
\end{tabular}

animals and in humans have demonstrated that acute and moderate alcohol consumption can transiently impair host defence against viral infections. ${ }^{9}$ Although the clinical implications of such a transient immunodepression are not completely understood, the epidemiological evidence adds insight into the putative consequences of alcohol consumption on HPV susceptibility.

There are both strengths and limitations in the present analyses. Because of the potential to report socially desirable responses, selfreported data have inherent biases that could lead to underreporting of alcohol consumption, tobacco use and number of sex partners. ${ }^{31} 32$ Additionally, FFQs are subject to random and systematic error, ${ }^{33}$ and differential misclassification of dietary intake is a concern if a study participant was aware of his/her disease status. However, differential misclassification would not impact the present findings as men were not aware of their HPV status during the administration of the Risk Factor Questionnaire and FFQ. Also, FFQs cannot estimate intake from the remote past and have been shown to introduce biased associations, ${ }^{34}$ so we attempted to reduce potential measurement errors attributable to recall bias by assessing intake during the year prior to enrolment into the study. We acknowledge that we cannot account for bias due to unmeasured or unknown confounding. Although we accounted for potential confounding by adjusting for self-reported sexual behaviour and stratifying by smoking status and lifetime number of sexual partners, residual confounding may still exist which could potentially inflate the observed point estimates. We also acknowledge that the US men in the HIM cohort may not be a representative of the general male population of the USA, which may limit the generalisability of our findings.

Overall, the results from these analyses demonstrated that high intake of alcohol is associated with an increased risk for prevalent HPV infections. Although these results cannot be considered causal and should be interpreted with caution, our findings do provide additional support to current public health messaging regarding the importance of moderate alcohol consumption, smoking cessation and safe sex practices. The biological mechanisms underlying the association between alcohol consumption and genital HPV infection remains understudied and limited epidemiological data exist, especially among men. Additional research is needed to replicate the current findings before clinical interventions can be recommended. Nonetheless, these data are important since there is limited information on the association between alcohol consumption and genital HPV infection in men and future longitudinal analyses will be needed to assess whether alcohol consumption is associated with HPV acquisition and clearance.

\section{Key messages}

- This analysis revealed that the highest quartile of alcohol consumption is associated with an increased risk for prevalent human papillomavirus (HPV) infections.

- We found no evidence of confounding by sexual behaviour and smoking following multivariable adjustment and stratification by these covariates.

- High alcohol intake was also associated with increased risk of HPV infection among never-smokers and current smokers.

- The observed effects among never-smokers are novel and of potential public health importance as there are few risk factors for HPV infection among never-smokers.

\section{Handling editor Jackie A Cassell}

Acknowledgements The authors thank the following staff members for their dedication in recruiting, examining and maintaining data on cohort participants, as well as conducting HPV DNA laboratory analyses: Kathy Eyring, CCRP; Christine Gage, ARNP; Nadia Lambermont, ARNP; Kim Isaacs, BA; Andrea M. Bobanic, BA; Kayoko Kennedy, BA and the Tissue Core staff of the Moffitt Cancer Center for their help in managing biological samples from the US site.

Contributors MBS, KME and ARG collaborated in the writing of this manuscript. MRP, BNT and MEA were involved in management of the cohort, data management and assisted in editing the manuscript. ARG was involved in project design and management as the principal investigator of the grant funding the project. MBS, ZJT, BNT and AN were responsible for data analysis. MBS, KME and ARG were responsible for data interpretation.

Funding This work was supported by the National Cancer Institute at the National Institutes of Health Grant (CA R01CA098803).

Transparency declaration The MBS (the manuscript's guarantor) affirms that this manuscript is an honest, accurate and transparent account of the study being reported; that no important aspects of the study have been omitted and that any discrepancies from the study as planned (and, if relevant, registered) have been explained.

Competing interests None.

Ethics approval University of South Florida.

Provenance and peer review Not commissioned; externally peer reviewed.

\section{REFERENCES}

1 Weinstock H, Berman S, Cates W Jr. Sexually transmitted diseases among American youth: incidence and prevalence estimates, 2000. Perspect Sex Reprod Health 2004;361:6-10

2 Shin HR, Franceschi S, Vaccarella $S$, et al. Prevalence and determinants of genital infection with papillomavirus, in female and male university students in Busan, South Korea. J Infect Dis 2004;1903:468-76.

3 Watson RA. Human papillomavirus: confronting the epidemic-a urologist's perspective. Rev Urol 2005;73:135-44. 


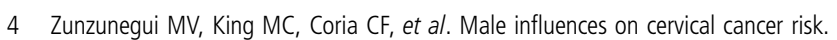
Am J Epidemiol 1986;1232:302-7.

5 Bosch FX, Castellsague X, Munoz N, et al. Male sexual behavior and human papillomavirus DNA: key risk factors for cervical cancer in Spain. J Natl Cancer Inst 1996;8815:1060-7

6 Agarwal SS, Sehgal A, Sardana S, et al. Role of male behavior in cervical carcinogenesis among women with one lifetime sexual partner. Cancer 1993;725:1666-9.

7 Stanley M. HPV_-immune response to infection and vaccination. Infect Agent Cancer 2010;5:19.

8 Dunne FJ. Alcohol and the immune system. BMJ 1989;2986673:543-4.

9 Szabo G. Alcohol's contribution to compromised immunity. Alcohol Health Res World 1997;211:30-41.

10 Cook RT. Alcohol abuse, alcoholism, and damage to the immune system--a review. Alcohol Clin Exp Res 1998;229:1927-42.

11 Diaz LE, Montero A, Gonzalez-Gross M, et al. Influence of alcohol consumption on immunological status: a review. Eur J Clin Nutr 2002;56(Suppl 3):S50-3.

12 Molina PE, Happel Kl, Zhang P, et al. Focus on: alcohol and the immune system. Alcohol Res Health 2010;331:97-108.

13 Nelson S, Kolls JK. Alcohol, host defence and society. Nat Rev Immunol 2002;23:205-9.

14 Giuliano AR, Lazcano E, Villa LL, et al. Circumcision and sexual behavior: factors independently associated with human papillomavirus detection among men in the HIM study. Int J Cancer 2009;1246:1251-7.

15 Giuliano AR, Lazcano-Ponce E, Villa LL, et al. The human papillomavirus infection in men study: human papillomavirus prevalence and type distribution among men residing in Brazil, Mexico, and the United States. Cancer Epidemiol Biomarkers Prev 2008; 178:2036-43.

16 Centers for Disease Control. Cigarette smoking among adults_-United States, 2000. MMWR Morb Mortal Wkly Rep 51;2002:642-5.

17 Centers for Disease Control. Quitting smoking among adults --- United States, 2001-2010. MMWR Morb Mortal Wkly Rep, 60;2011:1513-19.

18 Block G, Hartman AM, Dresser CM, et al. A data-based approach to diet questionnaire design and testing. Am J Epidemiol 1986;1243:453-69.

19 Gravitt PE, Peyton CL, Alessi TQ, et al. Improved amplification of genital human papillomaviruses. J Clin Microbiol 2000;381:357-61.

20 Gravitt PE, Peyton CL, Apple RJ, et al. Genotyping of 27 human papillomavirus types by using $\mathrm{L} 1$ consensus $\mathrm{PCR}$ products by a single-hybridization, reverse line blot detection method. J Clin Microbiol 1998;3610:3020-7.
21 Nielsen A, Munk C, Jorgensen $\mathrm{H}$, et al. Multiple-type human papillomavirus infection in younger uncircumcised men. Int J STD AIDS 2013; 24:128-33.

22 Ho GY, Bierman R, Beardsley L, et al. Natural history of cervicovaginal papillomavirus infection in young women. N Engl J Med 1998;3387:423-8.

23 Burkett BJ, Peterson CM, Birch LM, et al. The relationship between contraceptives, sexual practices, and cervical human papillomavirus infection among a college population. J Clin Epidemiol 1992;4511:1295-302.

24 Bairati I, Sherman KJ, McKnight B, et al. Diet and genital warts: a case-control study. Sex Transm Dis 1994;213:149-54.

25 Sikstrom B, Hellberg D, Nilsson S, et al. Smoking, alcohol, sexual behaviour and drug use in women with cervical human papillomavirus infection. Arch Gynecol Obstet 1995:2563:131-7.

26 Tolstrup J, Munk C, Thomsen BL, et al. The role of smoking and alcohol intake in the development of high-grade squamous intraepithelial lesions among high-risk HPV-positive women. Acta Obstet Gynecol Scand 2006;859:1114-19.

27 Schabath MB, Villa LL, Lazcano-Ponce E, et al. Smoking and human papillomavirus (HPV) infection in the HPV in Men (HIM) study. Cancer Epidemiol Biomarkers Prev 2012;211:102-10.

28 Vaccarella S, Herrero R, Snijders PJ, et al. Smoking and human papillomavirus infection: pooled analysis of the International Agency for Research on Cancer HPV Prevalence Surveys. Int J Epidemiol 2008;373:536-46.

29 Winer RL, Lee SK, Hughes JP, et al. Genital human papillomavirus infection: incidence and risk factors in a cohort of female university students. Am J Epidemiol 2003; 1573:218-26.

30 Giuliano AR, Sedjo RL, Roe DJ, et al. Clearance of oncogenic human papillomavirus (HPV) infection: effect of smoking (United States). Cancer Causes Control 2002;139:839-46.

31 Furnham A. Response bias, social desirability and dissimulation. Pers Individual Differences 1986;73:385-400.

32 Strecher VJ, Becker MH, Clark NM, et al. Using patients' descriptions of alcohol consumption, diet, medication compliance, and cigarette smoking: the validity of self-reports in research and practice. J Gen Intern Med 1989;42:160-6.

33 Lagiou P, Trichopoulou A, Trichopoulos D. Nutritional epidemiology of cancer: accomplishments and prospects. Proc Nutr Soc 2002;612:217-22.

34 Giovannucci E, Stampfer MJ, Colditz GA, et al. A comparison of prospective and retrospective assessments of diet in the study of breast cancer. Am J Epidemiol 1993;1375:502-11. 